\title{
THE PROCESS AND IMPORTANCE OF MARRIAGE COUNSELLING FOR MARRIED COUPLES: AN OVERVIEW
}

\author{
Ganesan Shanmugavelu ${ }^{1}$, Phd \\ Senior Lecturer,Institute of Teacher Education Ipoh Campus, Malaysia
}

\author{
Amuta Arumugam ${ }^{2}$ \\ Masters Student,Universiti Utara Malaysia
}

Article DOI: https://doi.org/10.36713/epra5915

\begin{abstract}
The aim of this study is to discuss the process and importance of marriage counselling for married couples. The use of marriage counselling were greater for persons with a positive attitude toward seeking marriage counselling and those who had previous marriage counselling. However, those having a supportive subjective norm were more likely to seek marriage counselling is the persons with no history of marriage counselling. Similarities and differences between males and females for the type of marital problem that might lead to marriage counselling and the implications for counsellors are presented. This study also determines the use of inquiry method in the counselling and counselling theories approaches. The research examined descriptive level specific problem areas for which an individual might pursue marriage counselling and how these varied by gender. Besides that, more general indices because it specifically targets beliefs about marriage be more strongly correlated to relationship variables (e.g., marital satisfaction) than have measures of generalized expectancies.
\end{abstract}

KEYWORDS : Importance, Marriage Counselling, Process, Behaviour, Attitude, Sex Differences

\section{INTRODUCTION}

Marriage counselling, also called couples therapy, is a type of psychotherapy that is conducted by licensed therapists. Usually involving both partners, marriage counselling helps couples to recognize underlying conflicts and improve their relationship. It can help married couples make thoughtful decisions, overcome differences and enrich communication between them. Online marriage counselling is also an ideal resource for relationship help. It's allowed couples connect with therapists online and works in a convenient, effective and time-saving manner. Marriage counselling give confidence inspires for both partners to focus on selfimprovement and self-awareness. Moreover, marriage counsellor is aware of the fact that couples come to them reluctantly, but with a hope that it can benefit their marriage. A good counsellor will make every effort to help the couple feel at ease and advise as best as possible to help couples address their problems in a better way. The advantages pursuing marriage counselling is to help comfort couples handle the challenges of married life and the goal is to get the relationship back on track. It's emphasized on the 'now' and the issues faced by couples recurrently. It's provides an opportunity for you to talk about your differences and compromises. In addition, what counselling does is help both to address their problems for a stronger and happier relationship plus helping the couple master the art of communication. Yes, basically counselling relief the trust or regenerate the flame, it is very effective about helping the couple cope up with the different types of stress experienced in the relationship. Usually marriage counselling is a shortterm focused treatment whereas therapies are a therapeutic process that can last several sessions. What makes it unique from marriage counselling is that it could go as far as addressing your individual 


\section{EPRA International Journal of Research and Development (IJRD)}

and personal issues to understand the behaviour you are showing in the relationship.

Marriages succeed once both partners take responsibility for nurturing the relationship and building an atmosphere of love and trust. Relatively just "going with the flow", partners take a proactive approach and strive to be the best they can be. But no one ever teaches us how to BE married after the GET married part is done. And once married, the understand why that is it's a difficult, individual, and evolving process. While does not claim to be an expert on love but hopes that the big lessons that husband and wife have learned in marriage counselling, perhaps can help and support others that want to make their marriage great. Honestly, marriage has been continuing to maintain symbolic importance for individuals living within and outside it, be an important focus of scientific inquiry and generate significant public interest and debate (Fincham \& Beach, 2010). The stigma with marriage counselling is that it's for couples that can't make it on their own, who's love life has crashed and is burning before their eyes. However, marriage counselling able to make a great marriage, truly hope this advice can strike a chord and make your marriage tremendous. It's highly encourages marriage counselling, which teaches us above all else, to pay attention to our emotions and talk them out. Most importantly the key reasons people seek therapy is for help with intimate and close relationships. And while marriage counselling tends to be viewed as something for only relationships in crisis, there are many reasons people in relationships might pursue it and deserve to be explored worked on.

The method involves pursuing marriage counselling were greater for persons with a positive attitude toward compare with those who had previous marriage counselling. At some point, you will experience rocky times for a few days, months or even years but the reality of two very different people living as a single unit is very challenging. Studies shown (1975; Ajzen \& Fishbein, 1980) the moment marital problem develops, why do married persons, as individuals or as a couple, not seek for marriage counselling? It can be explained that the inquiry method emphasizes conceptual framework within which to explore determinants of behavioural choices that identify two determinants of intentions, attitudes toward performing the behaviour (example "a person's general evaluation toward the behaviour," Ajzen \& Fishbein, 1980, p. 55) and subjective norms associated with the behaviour (example "a person's perception that important others desire the performance or non-performance of a specific behaviour," Ajzen \& Fishbein, 1980, p. 57).

What is important is that the method also involves attitudes, they argue that a general attitude will not predict a specific behaviour as well as the attitude toward the specific act. Furthermore, the comparative importance of the attitudinal and normative components can vary. Under some circumstances the normative component may be more important than the attitude, whereas, for other persons, behaviours, or contexts of the attitudinal component may be more important than norms. According to researcher Halgin, Weaver, Edell, and Spencer (1987) found the attitudinal element to be related to help-seeking from a professional psychologist, but they did not compute the normative component of the model. The entire application of the model intentions by pursue marriage counselling provided means for better understanding why individuals do and do not intend to pursue counselling. By evaluating the point to which attitudes and subjective norms are associated with intentions. The attitude toward an act can be measured either directly as the person's feeling toward the act, or indirectly as a composite of the person's beliefs about the consequences of the act and feelings about those consequences. Whereby, parallel to subjective norms can be assessed either directly as the net effect of expectations that important, others hold about the person performing the behaviour, or indirectly by assessing the person's knowledge of normative beliefs particular. Whereby, others have concerning the behaviour and the person's motivation to comply with those expectations.

Mainly the other hand, they may be more likely to try various interventions (including self-help and professional-help) because of a belief that something will work. Fischer and Turner (1970) found that those persons with an internal locus of control had a more positive attitude toward pursuing for help from professionals. Studies shown, Miller, Lefcourt, Holmes, Ware, and Saleh (1986) married persons with an internal locus of control versus an external locus of manage to constrict more active and direct in their problem solving as well more effective in communicating towards achieving goals. In general, the method has important goals in marriage counselling therapy theories as technique for quickly sifting through the tremendous amount of information that brings in marriage counselling, then follow by targeting specific thoughts, behaviours, or emotional processes for change and finally helping clients effectively make these changes to resolve their initial concerns. In spite of this, changing landscape of mental health care has altered how therapy theories are understood and used. Specifically, how theory being used and understood has been competent therapy with marriage people involves learning to conceptualize not only the psychology of the individual but also the complex web of relationships that constitutes a person's social 


\section{EPRA International Journal of Research and Development (IJRD)}

world and the interaction between the two (Gehart,2011).

\section{DESIGNING PLANNING STRATEGY (a) WHEN Should Pursue Marriage Counselling?}

Timing is an essential element in whether marriage counselling works. Almost couples wait too long to reach out for help repairing their marriage. Relationship and marriage expert couples take approximate six years to build up resentment before they begin the important work of learning to resolve differences in effective ways. Practically, it is critical that couples see conflict as an inevitable part of a committed, romantic relationship. In fact, most relationship has its ups and downs, and conflict goes with the territory. In spite of that yet couples might avoid conflict because it may have signified the end of their 'parents' marriage or led to bitter disputes (Michele Weiner Davis August 2002), explains that avoiding conflict backfires in intimate relationships. She also speculates that bottling up negative thoughts and feelings doesn't give your partner a chance to change their behaviour. On the hand the alert of the secrets of a good marriage or romantic relationship is learning to choose battles wisely and to distinguish between petty issues and important ones. Somewhat they becoming defensive and hurtful, they pepper their disputes with flashes of affection, intense interest, and mutual respect. Many people believe that should seek marriage counselling when separation or divorce are looming. But that is often too late. Marriage counselling therapy should begin as soon as the problems get in the way of your daily life. Here are some signs that you might benefit from a counselling therapy:

i. You have trouble expressing your feelings to one another

ii. You have one or more unsolvable disagreement

iii. There is withdrawal, criticism, or contempt in your interactions

iv. A stressful event has shaken your daily life

v. You have trouble making decisions together

vi. You experienced infidelity, addiction, or potential abuse

vii. You want a stronger relationship

Remember that there are no wrong reasons to seek marriage counselling. Specifically, some couples start therapy as soon as they are married, even without obvious problems, to prevent serious problems from developing. Therapist can help them become a better communicator, develop strong relationship skills, and improve your family's happiness. Therefore, it is important to acknowledge problems early and seek therapy as soon as possible.

\section{(b) HOW can marriage counselling} help couples?

In some marriage counselling to be effective, both partners need to be willing to take responsibility for their part in the problems, to accept each other's faults, and to be motivated to repair the relationship. It's significant for couples to have realistic expectations because it takes more than a few sessions to shed light on the dynamics and to begin the process of change.

i. A motivated couple can begin to explore their problems from a new perspective.

ii. They can learn new ways to recognize and resolve conflicts as a result of the tools provided by the therapist.

iii. Partners can improve communication that may have eroded the quality of their interactions. Practically couples to reach an impasse and lose the ability to be vulnerable and trusting of one another.

iv. It can provide "neutral territory" to help couples work through tough issues or to put aside "baggage" that prevents the couple from moving on.

v. Couples can resolve to rebuild their marriage and make a renewed commitment, or clarify the purpose why they need to separate or end the marriage.

\section{DESIGNING GOAL AND TARGET METHOD}

(a) What you can expect

Marriage counselling brings couples or partners together for joint therapy sessions and working with a therapist, learn the skills to solidify own relationship, such as:

- Open communication

- Problem-solving

- How to discuss differences rationally

Together couples will learn how to identify problems without blame and instead examine how things can be improved. The importance of making the decision to go to marriage counselling can be tough. Uncertainty troubled in relationship, seeking help is more effective than ignoring the problems or hoping they get better on their own. Taking the first step by admitting the relationship needs help is the hardest part. Almost individuals find the experience to be insightful and empowering. Scheduling time to work on resolving conflicts in a healthy way is hard work but the payoff is tremendous. The desire from relationship can happen much more smoothly when give it time, as opposed to condensing plans into irrational timeframes. Basically, relationships can bring joy, but when there are communication or conflict resolution problems, that joy has the potential to turn into frustration and disappointment. 


\section{EPRA International Journal of Research and Development (IJRD)}

Great communication is essential in a long-lasting relationship. However, those skills do not always come naturally and should learn how to express your thoughts and feelings effectively as well learn how to understand and interpret your spouse's emotions. This is something that marriage counselling can help to do. Marriage counsellor will act as an interpreter, bridging the gap between and together, learn how to improve the flow of communication so that it can resolve conflicts in the future.

(b) Benefits of Marriage

\section{Counselling}

i. Identify the Root Cause of Marital Disputes. Marital disputes may not be as they appear on the surface perhaps, it may appear angry about your husband not doing the dishes, but really, you feel that there is an imbalance of household responsibilities. This may seem upset about your wife's recent shopping trip, but the actual issue is the financial stress you're experiencing. Marriage counsellor will help things get to the root of the issue so able to overcome the conflicts at the source.

ii. Bring Closure to Past Disputes. Are issues from the past continuing to affect the relationship in the present? If so, should bring closure to those events. Sometime issues like trauma, abuse, or infidelity, may be harder to overcome than others. However, this can get through these obstacles with the help of an experienced marriage counsellor.

iii. Find Personalized Solutions for Ongoing Obstacles. Perhaps the biggest focus of marriage counselling is finding what works for the relationship specifically. Personalities and lifestyles dictate what strategies work best for all. Obviously, this may not work for another couple. Marriage counselling will help find communication and time management strategies that work for lives as not just getting generic advice but may getting a tailored guide from a trusted advisor.

iv. Balance Stress and Responsibilities in the Relationship. From time to time we all experience the stress. In a marriage, the opportunity to share some of that stress with another person so do not carry the weight alone. It's significant to create a balance of responsibilities, including finances and household tasks but the nature of that balance is different for most of couple. It may carry out to find what works for? Marriage counselling help to establish a healthy balance that ensures both have a positive experience.

Marriage counselling is designed for couples of all ages and all walks of life. Relationship process and understand need to maintain a fulfilling marriage goal as well target. Go through specific process, marriage counsellor can teach those skills while monitoring counselling progress, mediating conflict and giving objective feedback.

\section{(c) Good Reasons to Pursue Marriage Counselling}

i. Deepen knowledge and understanding of yourself, your partner and your relationship.

ii. Structure communications to allow each to feel safe enough to empathically connect.

iii. Identify one another's fears and know what each needs to feel safe in the relationship.

iv. Make distinctions between making requests versus demands, sharing versus venting, connecting versus complaining.

v. Talk together and listen in a way that each feel accepted, validated and understood.

vi. Identify one another's triggers and defence strategies.

vii. Examine how wounds in childhood effect how each currently relates in your couple relationship.

viii. Identify and replace limiting beliefs or judgments with ones that energize to cocreate a mutually enriching relationship.

ix. Discover and embrace disowned, repressed or rejected parts of yourself that do not allow to feel safe enough to fully love and honours.

x. Identify limiting subconscious scripts and beliefs that block communications and cause reactivity and defensiveness.

xi. Find balance between yearnings to be loved versus be accepted and valued as a unique contributor.

xii. Understand what need to feel loved and clearly articulate that to partner.

xiii. Identify and replace old habits, defences and coping strategies with enriching ones.

xiv. Understand distinctions between healthy versus unhealthy expressions of anger.

xv. Rediscover the romance and the fun in relationship.

\section{(d) Empirically Proven Benefits}

The psychotherapy effectiveness and other forms of counselling has been debated the metaanalyses that brought empirical proof of the benefits experiences from undergoing mental health counselling (Brown, 1987). The design analytical information misinterpretation of Freudian speculation has tainted the modern understanding of the benefits of psychotherapy (Shedler, 2010). There are many benefits that some may not realize due to the stigma 


\section{EPRA International Journal of Research and Development (IJRD)}

that remains specifically around psychoanalytical methods of counselling. The following features were reliably noted as efficacy:

i. A focus on affect and expression of emotions on cognitive factors, psychoanalysis focuses and feelings.

ii. Evaluation of attempts to avoid distressing thoughts and feelings.

iii. Identification of patterns and recurring themes in emotions.

iv. Discussion of past experience with a developmental focus.

v. A focus on interpersonal relations.

vi. A focus on the therapeutic relationship.

vii. Safe exploration of fantasy life.

The empirical expectations of the American Psychological Association, was established task force to focus on effective interventions in the 1990s. This generate the movement called the empirically validated treatment (EVT) (Wampold et al., 2002). It was seven principles were provided to aid in the classification that determining scientific validity for interventions.

i. When evaluating intervention outcomes, a level of specificity must be considered. Compilation of evidence of the efficacy interventions be categorized from a broad categorization to a refined and more specific categorization.

ii. The level of specificity should not be limited to DSM diagnosis. This code enables practitioners to consider the whole person in treatment, rather than providing interventions based solely on the disorder they are treating.

iii. Scientific evidence needs to be determined in its entirety, as all studies will face difficulties.

iv. Absolute vs. relative efficacy needs to be presented.

v. Causal attributions for specific ingredients should be made only if the evidence is persuasive. The common factors in comparison to particular claims of individual components of an intervention causing the desired outcome.

vi. Outcomes should be assessed broadly with one intervention for stress should affect all other aspects of life.

vii. Regions will present differences in outcomes and should be assessed along with freedom of choice.

These are the important principle to understand that practitioners should always consider the broader picture of a client. The perspective of science that is interwoven with the personal approach and specific understanding of individual experience is vital for outcomes to be desirable and effective. In despite the fact an intervention may work well with one client, another may find it completely inappropriate and unhelpful to their circumstances.

\section{IMPLEMENTATION OF MARRIAGE COUNSELLING METHOD}

\section{Identify Problems and Information}

(a) Empirically proven that positive psychology studies have specific interventions that increase happiness and decrease depressive symptoms (Seligman, 2005). It was recommended early that in the hands of a skilled clinician or coach, the effects of specific interventions would improve outcomes for clients. This research studies utilizing random controlled, placebo assignment design proven with solid science that happiness interventions work. Thus, the work done within the therapeutic relationship with positive psychology interventions potentially have compelling value in improving wellbeing.

(b) Empirically proven that the reduction in chronic pain has been benefit of interventions in CBT (Ehde et al., 2014). The delivery of interventions variations concerning chronic pain have shown improvement in the adaptation to that pain in various populations. The practitioners can improve Skilled CBT underserved populations with improved knowledge in the field. The APA has teams in place to determine how evidence is collected ensures that couples in the field are getting information that is applicable.

\section{Design Hypothesis Method}

i. Increased skills in interpersonal communication.

ii. Improved interpersonal relationships.

iii. Decreased depressive symptoms.

iv. Decreased anxiety symptoms.

v. Reduction in pharmaceutical interventions.

vi. Improved quality of life.

vii. Clarity of behavioural contribution to wellbeing.

viii. Reduction of suicidal ideation.

ix. Improvement in emotional self-regulation.

$\mathrm{x}$. Reduction in substance misuse.

xi. Improved communication and social skills

xii. Support network and social encouragement

xiii. Relatability and improvements in healthy behaviours

xiv. Increases in perspective due to diversity in group dynamics 


\section{EPRA International Journal of Research and Development (IJRD)}

xv. Affordability of care (Thimm \& Antonsen,
2014)
xvi. Safe space to develop assertiveness and
appropriate boundaries through self-insight
xvii. $\quad \begin{aligned} & \text { Holding back some secrets or probably } \\ & \text { afraid to talk }\end{aligned}$
xviii. $\quad \begin{aligned} & \text { Partner is withholding affection as a } \\ & \text { punishment }\end{aligned}$
xix. Having an affair or contemplating it
xx. Always having discussions that always turn
negative
xxi. Still love your partner and really want things
to take a positive turn

3. Analyse, evaluate and interpret data or information

i. Helping people to articulate why they are seeking for counselling help

ii. Formulating goals and expectations for treatment

iii. Teaching clients how to get the most from the counselling experience

iv. Developing a high degree of trust and favourable expectations for change

v. Diagnosing those concerns and dysfunctional areas in need of upgrading

vi. Exploring the client's world, including past and present functioning

vii. Understanding the cultural context (gender, ethnicity, race, religion, socio-economic, class, sexual orientation, etc.) of the client's experience

viii. Examining the underlying family and systemic factors that are both contributing to the problems and providing potential resources

ix. Discussing underlying issues and concerns, as well as their meanings

$\mathrm{x}$. Supporting and accepting the client as a person while selectively reinforcing those behaviours that are most fully functioning

xi. Confronting inconsistencies in the client's thoughts, language, behaviour and feelings.

xii. Challenging assumptions that are inappropriate, self-destructive, counterproductive or irrational

xiii. Uncovering hidden and unconscious motives behind actions

xiv. Encouraging clients to accept greater responsibility for their choices and actions

$\mathrm{xv}$. Developing more options, as well as narrowing alternatives to those that are most suitable

xvi. Providing honest, constructive feedback

xvii. Structuring opportunities for practicing new ways of acting and being

xviii. Facilitating greater independence in the client so that counselling ends in the most efficient period of time

\section{THE ROLE OF MARRIAGE COUNSELLOR}

Although all relationships are difficult in some form or another, there will be disagreement, conflict, and hurt even in the best of times. Marriage counselling can help individuals and couples grow and heal. Counsellor has a lot of roles to play in a marriage relationship, ranging from being a leader, guardian and a guide for the couples. Most importantly, counsellor duty to act as a leader rather than just a therapist. This is the reason why counsellor's roles in a marriage relationship really matters. Counselling provide an open ground through which the couples can express their feeling as it is in their heart. This process will allow the couples to understand each other better after the feedback has been shared for them to see. One thing about marriage counselling is that to be careful while you counsel couples. This is very important so that not end up ending a marriage rather than strengthening it. As a highly skilled counsellor, will need to control the situation during the discussion so that each of the couples will not fill intimidated and betrayed. One of other important act is observe to strategize professional suggestions to couples upon how to improve their marriage relationship. Marriage counselling consider benefit for any couple and can promote mutually change for years. Therapist should provide a platform through which the couples will have a long time communicating together and they should discuss many issues between themselves. Impose them to understand that it is through effective communication that will be able to strengthen their relationship. This is very important for a therapist to be mindful of the kind of role he plays while counselling the couples.

Behaviour and the choice of how a couple interacts is a shift that can be beneficial in couples counselling. Dysfunctional interaction can sometimes lead to violence and other potentially dangerous behaviour. Counsellors can improve relationships by reducing the occurrence of these behaviours. Another benefit of marriage counselling is in the area of emotional avoidance. Through a good counsellor, marriages can improve by decreasing this avoidance. Lacking of proper speaking skill among each other, couples can develop poor habits in communication that create more conflict that further deteriorates the marriage bond. Counselling gives couples a framework for "how" communication play role in their counselling moments. Counselling with couples also allows focusing on a relationship's strengths. Within every relationship, some things work well. 


\section{EPRA International Journal of Research and Development (IJRD)}

Volume: 5 | Issue: 12 | December 2020

- Peer Reviewed Journal

EVALUATING HYPOTHESIS BASED ON HEALING THERAPIES

a) Psychoanalysis and

\section{Psychodynamic}

These approaches are based on the concept that unconscious beliefs, underlie maladaptive thoughts and behaviours. Gaining an insight into these beliefs can explain and relieve problems. The therapist and client also work to develop healthier ways of dealing with these previously repressed feelings and foster the client's inner resources and capability to manage their troubles.

- Psychoanalysis - Sigmund Freud developed his "talking therapy" that deconstructing and rebuilding the client's entire belief system. It benefits those who are robust of mind with an outwardly successful life but aware of long-term niggles or torments such as an inability to stay in a relationship. Freud compared the mind to an iceberg. The concept of the iceberg that actual visible above the water represents just a tiny portion of the mind, while the huge expanse of ice hidden underneath the water represents the much larger unconscious. Freudian theory also divides human personality up into three major components such as id, ego, and superego.

- Psychodynamic - An analytic psychology Carl Jung branch the basement of the belief that balancing a person's psyche would allow person to reach his/her full potential. The adaptation and balance of dual aspects of personality attain an entirety. Jung believe that individual people are more likely to be content, responsible and principled. The aspects of darker mind that most people hide which often clash with the conscious ego and the shadow. Therapist role is to help the couples use the archetypes to understand and change their own behaviour make positive changes to restore the balance.

\section{b) Cognitive and Behavioural Therapist (CBT)}

These therapist stem from the belief that it is not the things that happen to a person that upsets them, it is the way they think about the things that happen to them that upsets them, and the meaning that they assign to their experience. Cognitive and behavioural therapies show people that they hold the power to change the way they think about things, and the they react and behave as a result of these thoughts. Among behaviourist approaches Albert Ellis and Aaron T. Beck gained popularity therapists, despite the earlier behaviourist rejection of "mentalistic" concepts in thoughts and cognitions. The main efficacy in Cognitive behavioural therapy is to help couples deal with overwhelming problems in a more positive way by breaking them down into smaller parts. This theory demonstrates useful and practical strategies that can be used in everyday life, even after the treatment has finished.

\section{c) Humanistic Therapist}

This approach prioritizes listening over observing. To this end, therapist use open-ended questions and qualitative tools to study personality and encourage the client to explore their own thoughts, emotions and feelings. The therapist sees the client as inherently capable of and responsible for achieving personal growth, and not as a set of flawed unconscious drivers. This theory explains how to cultivate a positive and constructive relationship by valuing their client, and showing genuine, unconditional, and positive regard. This environment nurtures the client's self-knowledge, confidence in their own choices and emotional development, so that they can self-actualize (fulfil their own potential). The limitations of Sigmund Freud 's psychoanalytic theory and B. F. Skinner 's behaviourism.

- $\quad \boldsymbol{S e l f - A}$ wareness - aims to enable client to acknowledge the personal choices available to them and to understand their own motivations and goals.

- Self-Acceptance - values the client to allow them to accept themselves, promotes self-regard and self-belief.

- Self-fulfilment and growth - help the client to harness their innate abilities and resources for self-development and improvement.

\section{d) Systemic}

The concept of "systems" approach enables people to work out issues arising from the interplay of relationships. Therapists achieve deeper understanding of problems by working with everyone in a system (family or group), hearing differing points of view and watching people interact. The advantage is allowed couples to explore their identity as part of a larger group and also has the advantage of strengthening their community network useful for issues that worsen with isolation, such as addiction. Among the pioneers Murray Bowen was the family therapy and a noted founder of systemic therapy.

\section{CONCLUSION}

The results of this research have implications for getting people to marriage counselling and keeping them in marriage counselling. Addressing personal beliefs about the positive consequences of marriage counselling and correcting misperceptions about marriage counselling 


\section{SJIF Impact Factor: 7.001| ISI I.F.Value:1.241| Journal DOI: 10.36713/epra2016 \\ ISSN: 2455-7838(Online) \\ EPRA International Journal of Research and Development (IJRD)}

Volume: 5 | Issue: 12 | December 2020

- Peer Reviewed Journal

is important. Marriage Counselling seeks to help people understand different views, appreciate each other's needs, and build on strengths to make useful changes for a harmonious life together. Through counselling and therapy, patterns of unhelpful emotions, attitudes and behaviour are discarded to be replaced with more favourable habits. It is often successful in reconstructing good relationships, especially for young teenagers and adults. The intention of this process is to help couples interact better and achieve an advance level of interactions that will improve their relationship going forward. Pursuing Marriage counselling will help people with open communication, addressing differences rationally, accepting that differences are a good thing, and taking problem-solving approaches to help solidify as strengthen their relationship. Beside there is an obvious crack in relationship that is proving too stubborn to patch, seek help. Almost people make the mistake of waiting too long before taking this step. The counselling process will also involve several steps and attempts to help modify dysfunctional behaviours, reduce emotional avoidance, and then to improve communication. In this research therapy techniques will comprise of a series of evidencebased approaches and processes structured to help people change how to see relationship and to see things in an objective manner

\section{REFERENCES}

1. Ajzen, I., \& Fishbein, M. (1980). Understanding attitudes and predicting social behaviour. Englewood Cliffs, NJ: Prentice-Hall.

2. Brown, J. (1987). A review of meta-analyses conducted on psychotherapy outcome research. Clinical Psychology Review, 7(1), 1-23.

3. Bowen, Murray (1966), "The Use of Family Theory in Clinical Practice", Family Therapy in Clinical Practice (reprint ed.), Lanham, MD: Rowman \& Littlefield (published 2004), pp. 147181.

4. Bowen, Murray (1974), "Toward the Differentiation of Self in One's Family of origin", Family Therapy in Clinical Practice (reprint ed.), Lanham, MD: Rowman \& Littlefield (published 2004), pp. 529-547.

5. Ehde, D. M., Dillworth, T. M., \& Turner, J. A. (2014). Cognitive-behavioral therapy for individuals with chronic pain: Efficacy, innovations, and directions for research. American Psychologist, 69(2), 153-166.

6. Fishbein, M., \& Ajzen, I. (1975). Belief attitude, intention and behavior: An introduction to theory and research. Reading, MA: Addison-Wesley.

7. Fischer, E. H., \& Turner, J. L. (1970). Orientations to seeking professional help: Development and research utility of an attitude scale. Journal of Consulting and Clinical Psychology, 35, 79-90.
8. Fincham, F. D., \& Beach, S. R. H. (2010). Marriage in the new millennium. Journal of Marriage and Family, 72 (3), 630-649.

9. Gehart, D. (2011b). The core competencies and MFT education: Practical aspects of transitioning to a learning-centered, outcomebased pedagogy. Journal of Marital and Family Therapy, 37(3), 344-354.

10. Gottman, J. \& Silver, N. (2015). The Seven Principles for Making Marriage Work: A Practical Guide from the Country's Foremost Relationship Expert. Random House: New York.

11. Halgin, R. P., Weaver, D. D., Edell, W. S., \& Spencer, P. G. (1987). Relation of depression and help-seeking history to attitudes toward seeking professional psychological help. Journal of Counseling Psychology, 34, 177-185

12. Miller, P. C., Lefcourt, H. M., Holmes, J. G., Ware, E. E., \& Saleh, W. E. (1986). Marital locus of control and marital problem solving. Journal of Personality and Social Psychology, 51, 161169.

13. Mayer, A. (2016). Marriage: Complete Guide for Saving and Rebuilding Trust, Intimacy and Connection. Amazon Digital.

14. Parrott, L. \& Parrott, L. (2015). Saving Your Marriage Before It Starts: Seven Questions to Ask Before - and After - You Marry. Zondervan: New York.

15. Shedler, J. (2010). The efficacy of psychodynamic psychotherapy. American Psychologist, 65(2), 98-109.

16. Seligman, M. E. P., Steen, T. A., Park, N., \& Peterson, C. (2005). Positive Psychology Progress: Empirical Validation of Interventions. American Psychologist, 60(5), 410-421.

17. Thimm, J. C., \& Antonsen, L. (2014). Effectiveness of cognitive-behavioral group therapy for depression in routine practice. BMC Psychiatry, 14(1).

18. Wampold, B. E., Lichtenberg, J. W., \& Waehler, C. A. (2002). Principles of Empirically Supported Interventions in Counseling Psychology. The Counseling Psychologist, 30(2), 197-217.

19. Weiner-Davis, Michele (August 2002). The Divorce Remedy: The Proven 7-Step Program for Saving Your Marriage. Google Books: Simon \& Schuster. pp. chapter 1. ISBN 978-0-684-873251 . 